\section{POLARIZATION OF GLOBIGERINA}

ON examining a group of ancient microscopic slides of modern foraminifers it was found that they polarize very beautifully, showing with plane polarized light several concentric circular spectra and a very clear black cross with broad bands and a broadened central area. This appeared most perfectly with globigerina, the young forms with but a single globe showing most perfectly. In the larger forms each half enveloping globe shows the same phenomena very clearly. The spectral rings are crowded toward the edge of the sphere and the explanation is clearly that the hollow sphere is in effect a circular wedge with its thinnest part at the center and becoming thicker radially, at first gradually and at last much more rapidly.

It was found also that minute valves of a bivalve, in shape like a quahog, would do exactly the same things only the rings were pear-shaped with a projection at the beak of the shell and broader and brighter. It was clear that the very sharp black cross was due to the fact that the outer layer of the shell is fibrous and we may deduce that the similar black cross in the globigerina is due to a minute fibrous structure in the shell of the latter.

Thin plates of the inner mother of pearl layer of Margaritifera and Pinna polarize brilliantly and give the lemniscate of a negative biaxial mineral with the axis at right angles to the layers, and so the mineral in all these cases is doubtless aragonite.

The smaller species of deep sea Globigerina show all this most beautifully and are a convenient object to demonstrate the stationary black cross and the higher order spectra in concentric rings. The silicious forms, Diatoms, Polycistina and sponge spicules do not polarize. This is true of the marine sponges like Aspergillum and Euplectella, but the freshwater sponge Grantia from the ponds around Amherst polarizes very strongly.

B. K. Emerson

AmHerst, Mass.

THE TEACHING OF THE HISTORY OF SCIENCE

To THE Editor of ScIEnce: In his interesting and valuable paper on "The Teaching of the History of Science" published in ScrENCE, November 26, 1915, Mr. Brasch calls attention to early courses in this subject which were given at the Massachusetts Institute of Technology, referring particularly as one of these to a reading course on the history of the physical sciences laid out as a requisite for graduation in the course in physics. The date which he mentions for its institution is $\mathbf{1 8 8 7 .}$

In fact, however, its beginning was much earlier. The writer from the outset of his work as a teacher had recognized the surprising lack of perspective existing among college students, but chiefly on account of the great pressure upon the teaching staff which existed here as everywhere, it was not possible at the time to institute a course of oral lectures upon the subject and the best that could be done was to lay out a suitable course of required reading, which was necessarily limited to physical science. This reading course was established at a considerably earlier date than that mentioned by $\mathrm{Mr}$. Brasch, and is found set forth in the Catalogue of the Institute for 1880-81 in the scheme of studies leading to a degree in physics. A required reading course upon the logic of scientific investigation is also referred to in the same scheme.

A similar course on the history of the natural sciences is referred to in the same catalogue of the Institute in the scheme of the course in natural history.

\section{R. Cross}

\section{SCIENTIFIC BOOKS}

\section{British Ants, Their Life-History and Classi-} fication. By H. ST. J. K. Donisthorpe. Plymouth: Wm. Brendon \& Son, Ltd., 1915. Pp. $x v+373,18$ pls. and 92 text-figs.

In this attractive volume we are given for the first time an exhaustive monograph of the ant-fauna of Great Britain, the result of many years of patient labor by one who served his biological apprenticeship as an ardent student of myrmecophiles. The volume serves also as a useful manual for the study of ants in general since it contains concise chapters on the anatomy, development and behavior of ants and the methods of keeping and studying 